\title{
Brief Discussion on Instantaneousness and Eternity of Photographic Works
}

\author{
Chaojie Wei \\ School of Art and Design \\ Huanghe Science and Technology College \\ Zhengzhou, China \\ e-mail: 895885469@qq.com
}

\begin{abstract}
Instantaneousness is crucial to photographic works, because moments of the shot objects are changing in motion state, that is, momentary beauty is varied and rich. The moment stressed by the writer is "the decisive moment", the most representative and wonderful moment in the development of things with inner link for things. Responsibility of photographer is to freeze the moment into eternity. A photographer who really has a good taste and comprehension and understands life, society and nature cannot but pay profound attention to time significance of photography and realize inner link between moment and eternity.
\end{abstract}

\section{Keywords—photographic works; decisive moment; eternity}

\section{INTRODUCTION}

In the development process of human civilization, photography extends human's vision as one technology directly recording visual image. Hence, human have the third eye to observe the world, observe fleeting development process of things and savor the pleasure brought by photography. If we say what is the most perfect product of combination of science and art? Nothing is better than photography. Process of science and technology makes us acquire images easier and easier; just its operability and reproducibility makes most people ignore social value, artistic value and humanistic connotation of photographic works, which needs us to distinguish ordinary photo, pure mechanical records from photographic creation.

\section{INSTANTANEOUSNESS IS MAIN CHARACTERISTIC OF PHOTOGRAPHIC WORKS}

From the perspective of ontology language of photography, instantaneousness is the most important characteristic of photographic creation distinguished from other art forms.

Famous photographer, Henri Cartier-Bresson once said, "A person or a thing has decisive moment. This moment determines the difference between this thing and others and determines its typical meaning." The mission of photographer is to "capture this moment and then capture that moment and the eyes of truth are always watching life." Bresson, the great photographer does not initiate theoretical system of "the decisive moment", but also succeeds to put this system into practice. The Return of a Boy after Buying Beer "Fig. 1" is one extremely common scene in urban life. On one Sunday, a child (obviously, very naughty) is assigned to buy beer on the street, but the precious is that Bresson, the author, captures the natural and true momentary mood of the child who is triumphant because of being entrusted with an important post, especially under the background of indistinct streetscape and praised eyes of the girls, the child's expression looks more prominent. This natural and vivid life scene moment affording a lingering after-taste is full of widespread optimistic mood of social life in 1950s European reconstruction period. Moment of the photographic works is just one moment with "typical meaning" and is one times condensation in 1950s European reconstruction period.

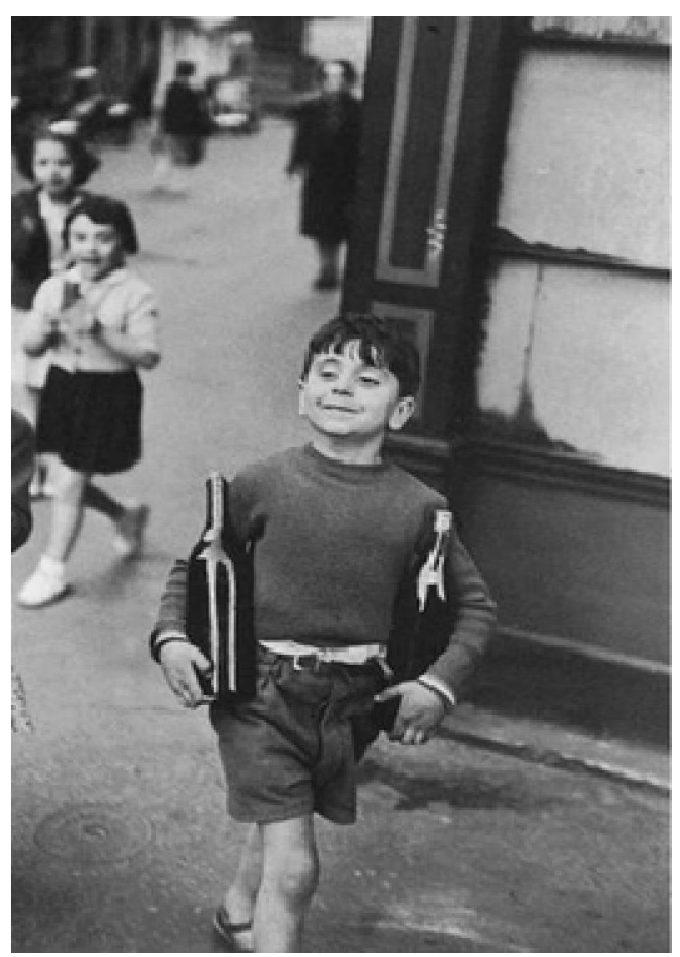

Fig. 1. The Return of a Boy after Buying Beer, shooting by Bresson

The works of Back Scene of Saint-Lazare Station "Fig. 2 " is not shot simply and casually in clever conception in composition, the directions of the protagonist's jump and the 
person's jump painted on the wall; reflection of fence ladder in the water, the arc of debris on the water and the arc of station ceiling in the distance, all are contrasts and complementing full of meaning. This works shows "the decisive moment" incisively and vividly. As for understanding of photography, Bresson said, "photography, in my opinion, is picture, is extemporaneous sketch, completed by intuition and not changeable." "Time is not reserved, and there is no maybe or perhaps in taking photos. All maybe shall be thrown into the dustbin." Bresson takes taking photos as one pleasure; he can find the most cardinal shooting angle quickly and press the shutter in the key moment of best combination effect of light ray formation and expressive power. Bresson emphasizes the importance of observation, "what counts is observation, photography is to show the most important part astutely in very short time." Theoretical system of "the decisive moment" created by the great photographer, Bresson, has influenced several generations of photographers since 20th century.

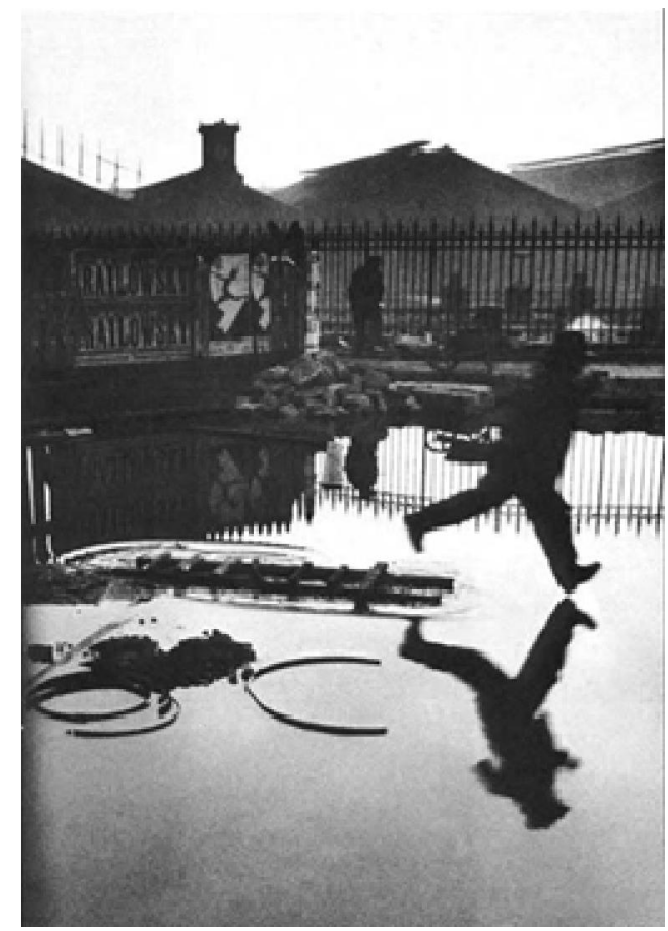

Fig. 2. Back Scene of Saint-Lazare Station, shooting by Bresson

Not only Bresson's works focuses on instantaneousness, works created by the representative of "Candid", Salomon and "civilian photographer" Robert Doisneau and others also emphasize instantaneousness. The figure who makes "candid photograph" the basic means of photography and stresses instantaneousness is Erich Salomon certainly, one German press photographer. During shooting, he never intervenes in the site and uses flashlight, but by virtue of dexterity of small camera and exposure capacity of fast lens with large diameter and existing light, he takes a candid photograph for the news event in real time. Because he tries not to be noticed by the subject before shooting, sometimes he even hides the camera under the briefcase and cloths, people also call his shooting method "candid camera". Once in a conference, French Foreign Minister Aristide Briand was asking why Salomon did not come, then Salomon just reached and subtly pointed to the scene, "Salomon is coming", this picture becomes one representative works of Salomon. Salomon's "Candid photograph" only stays in the surface of image and does not truly mine the relationship between inherence and instantaneousness of things.

"Class is not over yet" is Doisneau's works in 1956 "Fig. 3". Look, the claspics is not over, but the boy in the classroom has been absent-minded, looks up at the clock on the wall and looks forwards to finish the class.

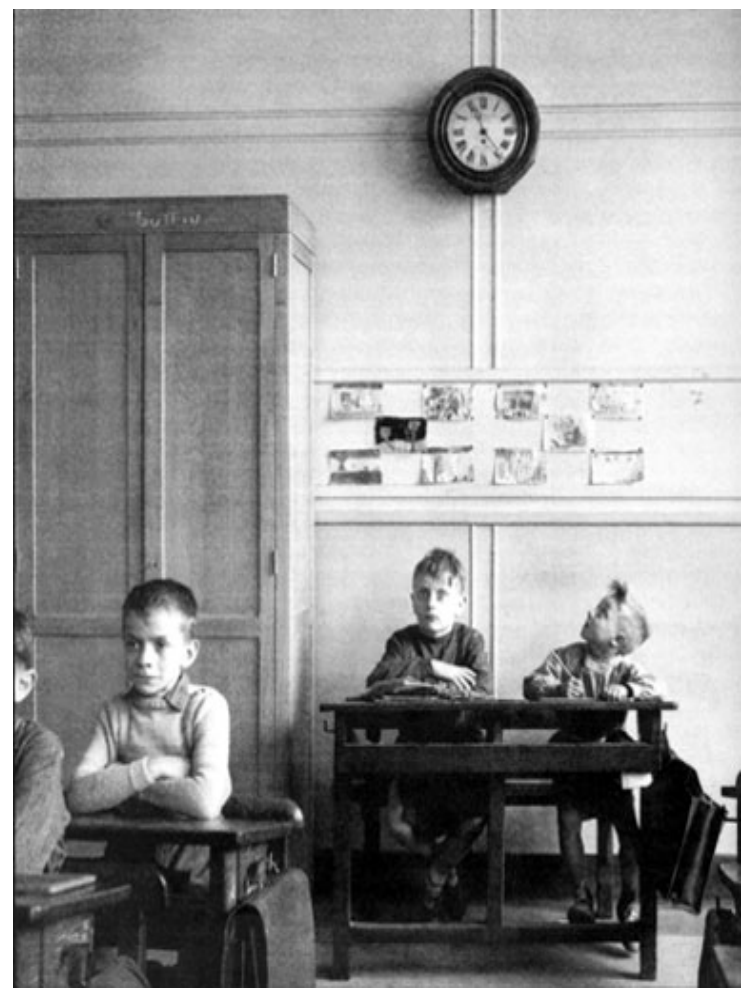

Fig. 3. "Class is not over yet"

This moment and mood will happen in students' learning life. Doisneau captures this moment which truly reflects lively and active nature of children. Doisneau often takes a candid photograph of wonderful moments in life humorously with the method of "fixing point, hiding and taking candid photograph.

\section{Aesthetic Meanings of "The Decisive Moment"}

From the perspective of aesthetic meanings, "the decisive moment" theory discussed in Bresson's works The Decisive Moment published in 1952 has more profound meaning. The famous British scholar Russell Miller once wrote, "this may be the most influential and important works in the photographic history... Insightful view points in the book have enlighten several generations of photographers in the world and bring them new concept and new taste." Bresson's comprehension for photography essence has reached higher aesthetic degree. In fact, from the day of birth of photography, people constantly discuss difference between 
photograph and painting and other visual arts. But before Bresson, people only make discussion in theme, contents, composition of picture, aesthetic characteristics and component elements and sense of form and then create some new ideas. No matter what the difference between photography and painting obtained from the discussion is, their essence is consistent, that is, both reflect threedimensional space through two -dimensional space and photography is specialized totally, which is the largest omission in the world photographic history, because since the day of birth, photography does not merely record the space, what's more important is time. Photograph recording corresponding time with exposed time history is bound to nature and is inherent. The more developed the photograph is, the more obvious the time function is and the stronger the aesthetic sense of time is. Until Stieglitz, Steichen, and Strand who have opened modern photography, momentary consciousness has held an important status. But it does not reach "decisive " meaning for the three people, but German "candid" brings moment into time sequence of event, which causes "process"; this time process only stays in visual image category and does not explore core and essence of things. Only Henri Cartier-Bresson analyzes "the decisive moment" in the continuous time process and discover the time, inherent potential of photograph and makes it become core idea of photography aesthetics. Bresson once said, "Taking photos is to capture changeable and passing reality when all conditions reflecting things essence are provided. Just this moment accurately captures the image essence." Obviously, Bresson's "image essence" is in the time process. Just introduction of momentary beauty of time makes the photography truly possesses its own soul, furthermore, the photography does not only break away from painting in contents and forms, but also has essential difference with painting and other visual arts in visual aesthetics attributes finally and is unique in the big art family.

\section{IV. “The DECISIVE MOMENT” CREATES ETERNITY OF PHOTOGRAPHIC WORKS}

Photography marks the beginning of true records for objective things by human since French government announced birth of photography on August 19, 1839. It directly captures the momentary scene seen by the eyes and realizes the dream of image preservation and copy for long time. Emergence of photography extends human's vision and expands human's observation depth and breadth. Emergence of photography injects new vitality into development of visual culture and makes creation of image become more convenient and efficient and changes the history of human making image considerably. "Recording" is one major function of photography, along with constant development, "education function" and "aesthetic function" of photography becomes increasingly prominent. People express their thought and feelings and reveal some phenomena through photographic works so as to inspire and educate people. With photography, we can observe the surrounding world from new view angle and examine ourselves; the photography greatly promotes development of visual image. However, no matter how develop the photography, its instantaneous characteristic does not change all the time, which is the inherent nature.

Photography is momentary modeling art. Photography can complete image records in a flash and turn the changing moments into eternity. Among all arts, only photography can finish with the movement of objective objects synchronously and freeze them into stationary and eternal images. "Turning the fleeting image into eternal artistic ideal" expected by French artist, Rodin has been reality in photographic works. Photography can reveal eternal momentary beauty in still image. Just this momentary beauty brands inerasable eternity in people's heart.

Instantaneousness is crucial to photography, because moments of the shot objects are changing in motion state, that is, momentary beauty is varied and rich. The moment stressed by the writer is "decisive moment", the most representative and wonderful moment in the development of things with inner link for things. Responsibility of photographer is to freeze the moment into eternity. A photographer who really has a good taste and comprehension and understands life, society and nature cannot but pay profound attention to time significance of photography and realize inner link between moment and eternity.

\section{REFERENCES}

[1] Zhou Xian. Orientation Change of the Visual Culture. Peking University Press:2008

[2] Bao Ku. Review. China Federation of Literary and Articles Press

[3] Wang Hongjian. Perspective. Culture and Art Publishing House: 2003

[4] Gu Zheng. A World History of Photography. Zhejiang Photographic Press: 2009

[5] Kang Daquan. Aesthetic Principles of Photography. Sichuan Fine Arts Publishing House: 2006

[6] Perspective. Wang Hongjian. Culture and Art Publishing House 2004

[7] Aesthetics. Hegel. (Volume One)

[8] A World History of Photography. Li Wenfang. Heilongjiang People's Publishing House 2014

[9] Photo Coursebook. Liu Lihong. China Photography Publishing House 2012

[10] Wang Hailong. Visual Anthropology. Shanghai Literature and Art Publishing House 2007

[11] Russell-Miller. The Eyes of the World. China Photography Publishing House 2001 